\title{
The Illustrations
}

The drawings used throughout this book are the work of a ten-year-old Tecospa lad. Since a primary objective of this study is to convey the concepts of the people about whom it is written, it was a particularly fortunate circumstance that these penetrating insights into the culture were available. Crispin Meza's pencil has done what neither words nor camera could do. Photographs are by the author.

A home altar. (photo) . . . . . . . . frontispiece

A housewife weaving a "faja" (sash) on a belt loom. (photo) . 2

A little girl grinds maize on an Aztec metate. (photo) . . . 5

$\begin{array}{llllllllll}\text { Composite picture of life in Tecospa. (sketch) } & \text {. } & \text {. } & \text {. } & \text {. } & \text {. } & & 7\end{array}$

A mother talks to the infant carried on her back in a rebozo. (sketch) 11

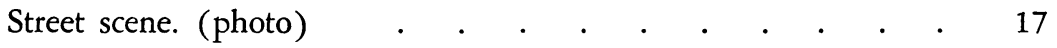

Tecospa boys at the foot of a cross. (photo) . . . . . 20

Dancers re-enact the Spanish dance "Los Moros y Cristianos."

(photo) . . . . . . . . . . . . 22

A seven-headed monster represents the Seven Deadly Sins. (sketch) 25

Cobblestone street. (photo) . . . . . . . . . . . 34

Sucking maguey juice into a hollow calabash. (photo) . . . 36

Closing the cavity of the maguey plant with a stone. (photo) . . $\quad 37$

Farmers at work. (sketch) . . . . . . . . . . 39

Harvesting maize. (sketch) . . . . . . . . . . . 40

Shelling and storing corn. (sketch) . . . . . . . . . 41

A church corn-shelling held beneath a family altar. (photo) . 42

Shelling corn on an "oletera" made of bound corncobs. (photo) . 43

"Barrel" made from the stump of a "milked-out" maguey. (photo) 45

Harvesting tunas. (photo) . . . . . . . . . 46

Butchering time. (photos) . . . . . . . . . . 48

Pig being prepared for butchering. (sketch) . . . . . 50

A shepherd's hut. (photo) . . . . . . . . . 51

View showing typical roofs. (photo) . . . . . . . . 56

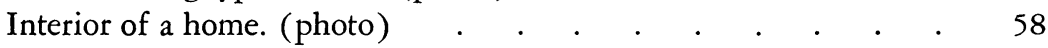

A corncrib. (photo) . . . . . . . . . . . . . . $\quad . \quad 59$

Charcoal-making in the "monte." (sketch) . . . . . . 61 
Bringing firewood from the "monte." (photo) . . . . . 62

Making shingles. (sketch) . . . . . . . . . 64

A tile roof, two girls, and a dog. (photo) . . . . . . . 66

The Witch of Tecospa and his wife. (photo) . . . . . . 68

A "temazcal" with its women occupants. (sketch) . . . . 70

A type of carryall common throughout much of Mexico. (photo) 72

A bare-bottomed baby. (photo) . . . . . . . . 74

A mother and her children. (photo) . . . . . . . 76

Ready for fiesta. (photo) . . . . . . . . . . 80

A boy carrying his brother in a rebozo. (photo) . . . . 83

Indian boys playing marbles. (photo) . . . . . . . 85

Children beside their mud toy house. (photo) . . . . . 87

Figs from the backyard. (photo) . . . . . . . . 89

The author's godchild. (photo) . . . . . . . . 92

Boy holding an animal-bladder balloon stands beside a hydrant.

(photo) . . . . . . . . . . . . 104

The Mayor of Tecospa. (photo) . . . . . . . . 106

Two husbands and a suitor. (photo) . . . . . . . 108

Community project. (photo) . . . . . . . . . 110

Co-operation: men at work. (photo) . . . . . . . . 111

A little girl climbs an uphill street. (photo) . . . . . 113

The new president of the Council of Catholic Neighbors celebrates.

(photo) . . . . . . . . . . . . 115

Standard-bearers and "coheteros." (photo) . . . . . . 116

The Mayor and his wife. (photo) . . . . . . . . 119

Bringing beams from the "monte." (sketch) . . . . . 121

Chopping firewood in the mountain forest land. (sketch) . . 122

Fiesta time: women pulque vendors. (photo) . . . . . 124

A big black Water Snake lashes the sky while Aztec rain dwarfs produce a storm. (sketch) . . . . . . . . . 129

Rain dwarfs leave their cave to tend their sheep. (sketch) . . 130

Rain dwarfs blow out the disease called "aire" and whip an Indian chosen to become a shaman. (sketch) . . . . . . . 132

Gentlemen cowboys, known as "charros." (sketch) . . . . 134

Religious procession honoring San Francisco. (photo) . . . 140

Worshipers kneel before a "posa." (photo) . . . . . 142

Young pulque vendors. (photo) . . . . . . . . 144

Religious procession at the village fiesta. (photo) . . . . 146 
A drummer and a "chirimítero" lead the procession for San Francisco. (photo) . . . . . . . . . . . 147

The drummer and chirimitero march in front of a "posa." (photo) 149

"Coheteros" on their way to fiesta. (photo) . . . . . 150

Tecospans on a pilgrimage to visit the Lord of Chalma. (sketch) 152

Carrying fireworks to fiesta. (photo) . . . . . . . 154

Amateur musicians from neighboring villages. (photo) . . . 157

Teutli, home of Aztec rain dwarfs. (photo) . . . . . 160

The world of nature and man. (sketch) . . . . . . 162

Shearing a sheep. (sketch) . . . . . . . . . . 163

Animals and plants are important in Indian folklore and beliefs. (sketch) . . . . . . . . . . . . . 170

Applying "sangre de pichon" (pigeon blood) to a patient. (sketch) 176

Curandera draws a curled snake with soot. (sketch) . . . . 177

An egg is used in curing the disease called "aire." (photo) . . 180

Treating a patient by means of a curing stone. (sketch) . . . 182

The Witch of Tecospa. (photo) . $\quad . \quad$. $\quad . \quad$. $\quad . \quad$. $\quad . \quad 192$

A transforming witch, called a "nagual," changes into a plant and stone. (sketch) . . . . . . . . . . . 194

The Witch's wife. (photo) . $\quad . \quad$. . . . . . . . $\quad . \quad 198$

A vampire witch, called a "tlacique," in action. (sketch) . . . 203

The vampire returns home for a blood meal. (sketch) . . . 204

Funeral procession for a child. (photo) . . . . . . 208

Journey to the next world on the back of a dog. (sketch) . . 211

Mourners at a wake. (sketch) . . . . . . . . 212

The village church illuminated with electric lights. (photo) . . 220

A blending of the old and the new. (photo) . . . . . 222 
THIS PAGE INTENTIONALLY LEFT BLANK 